\title{
Additive effect of anti-citrullinated protein antibodies and rheumatoid factor on bone erosions in patients with RA
}

\author{
Carolin Hecht, ${ }^{1}$ Matthias Englbrecht, ${ }_{1}^{1}$ Jürgen Rech, ${ }^{1}$ Sarah Schmidt, ${ }^{1}$ \\ Elizabeth Araujo, ${ }^{1}$ Klaus Engelke, $^{2}$ Stephanie Finzel, ${ }^{1}$ Georg Schett ${ }^{1}$
}

\begin{abstract}
Handling editor Tore K Kvien
- Additional material is published online only. To view please visit the journal online (http://dx.doi.org/10.1136/ annrheumdis-2014-205428).

${ }^{1}$ Department of Internal Medicine 3, University of Erlangen-Nuremberg, Erlangen, Germany

${ }^{2}$ Institute of Medical Physics, University of ErlangenNuremberg, Erlangen, Germany
\end{abstract}

\section{Correspondence to} Georg Schett, Department of Internal Medicine 3, University of Erlangen-Nuremberg, Erlangen; Ulmenweg 18 Erlangen 91054, Germany; georg.schett@uk-erlangen.de

Received 17 February 2014 Revised 23 June 2014 Accepted 20 July 2014 Published Online First 12 August 2014

\section{CrossMark}

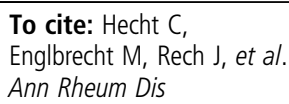

\section{ABSTRACT}

Objective To determine whether there is an additive effect of anticitrullinated protein antibodies (ACPA) and rheumatoid factor (RF) on the number and size of bone erosions in patients with rheumatoid arthritis (RA)

Methods 242 patients with RA received highresolution peripheral quantitative $\mathrm{CT}$ (HR-pQCT) scans of the metacarpophalangeal joints. Demographic and disease-specific parameters including ACPA and RF levels were recorded from all patients. Erosion numbers and their size were assessed in 238 patients at 714 individual joints (MCP 2, 3 and 4) and 5712 sites (each 4 quadrants in metacarpal heads and phalangeal bases). The volume of erosions was calculated by a semiellipsoid formula.

Results Of the 238 patients, 112 patients showed RF and ACPAs (ACPAs+RF+), 28 only RF (RF+), 29 only ACPAs (ACPA+) and 69 were antibody negative (NEG). Erosion number and size were highest in RF+ACPAs+ patient group with significant differences compared with NEG patients with respect to erosion number $(p=0.001)$ and to ACPA-negative patients with respect to erosion size $(p<0.001)$. Results maintained significance in a linear mixed model showing ACPAs+RF+ status and disease duration being associated with higher number ( $p=0.017$ and $p=0.005$, respectively), and larger size ( $p=0.014$ and $p=0.013$, respectively) of bone erosions. Furthermore, erosion size was influenced by the presence and titre of RF only in ACPA-positive patients with RA but not in ACPA-negative patients.

Conclusions ACPAs and RF show an additive effect on erosion number and erosion size. Concomitant presence of ACPAs and RF is associated with higher erosive disease burden in patients with RA. Furthermore, RF influences erosion size only in ACPA-positive but not in ACPA-negative patients.

\section{INTRODUCTION}

Rheumatoid arthritis (RA) is a chronic inflammatory disease characterised by inflammation of the synovial membrane and bone loss. ${ }^{1-3}$ This debilitating process strongly impacts patients' quality of life. Presence of autoantibodies, such as anticitrullinated protein antibodies (ACPA) as well as rheumatoid factor (RF) are hallmarks of the disease indicating break of immune tolerance. ${ }^{1}{ }^{4} 5$ Although not all patients with RA develop immune responses against self, its presence is indicative for a more severe disease course. Criteria for the classification criteria of RA have therefore included autoantibody responses such as ACPAs and RF. ${ }^{6}$

The link between autoantibodies and more severe disease course of RA is at least, in part, based on a higher likelihood for structural damage. Although structural damage in patients with RA also depends on disease activity, presence of autoantibodies is an independent predictor of structural deterioration of the joint. Both $\mathrm{ACPAs}{ }^{7-12}$ and $\mathrm{RF}^{13-18}$ are associated with bone damage in RA. For ACPAs, mechanistic insight has been recently obtained, showing that ACPAs directed against citrullinated vimentin induce the differentiation of bone resorbing osteoclasts, thereby triggering bone loss. ${ }^{19}$ Bone damage in early and even recent-onset RA has been attributed to ACPAs, which form years before arthritis starts and clinical symptoms start to emerge. ${ }^{20-22}$ Even before the clinical onset of arthritis, ACPAs are associated with bone loss ${ }^{12}$ and alterations in bone metabolism $^{23}$ suggesting that these antibodies are indeed strongly and most likely independently linked to structural bone damage in RA.

Whether RF also influences bone damage in patients with RA is less well defined. RF has been associated with bone loss, but the relation of its effect to ACPAs is unclear. Due to the substantial overlap between ACPAs and RF positivity, it may well be that ACPAs confound the effect of RF and vice versa. RF is an immune complex per definition, and cross-linking of Fc-receptors on the surface of monocytes has shown to trigger the release of inflammatory cytokines, some of them, like tumour necrosis factor- $\alpha$ (TNF- $\alpha$ ) may trigger pro-osteoclastogenic effects. Thus, also RF could be directly involved in bone loss in RA. ${ }^{24}$

To tackle the question how whether RF also triggers local bone erosion in RA, and whether such effects depends on the presence of ACPAs, we examined the prevalence and size of bone erosions in four groups of patients with RA: those exhibiting both ACPAs and RF response, those with isolated $\mathrm{RF}$ or isolated ACPAs and those lacking both autoantibodies. Periarticular bone erosions in the metacarpophalangeal joints (MCPs) were assessed for prevalence and 3-dimensional size by applying highresolution peripheral quantitative CT (HR-pQCT).

\section{MATERIALS AND METHODS}

\section{Patients}

Between 2011 and 2013 all patients with the diagnosis of RA, fulfilling the new American College of 
Rheumatology/ European League Against Rheumatism classification criteria ${ }^{6}$ at the Department of Internal Medicine 3 of the University of Erlangen-Nuremberg were invited to perform an HR-pQCT scan of their MCPs. Demographic characteristics such as age, gender and body mass index and disease-specific information such as disease duration, disease activity measured by the disease activity score 28 (DAS28), anti-rheumatic treatment (conventional and biological disease modifying antirheumatic drugs, DMARDs) and presence/absence of ACPAs and RF were recorded. The local ethics committee of the University Clinic of Erlangen approved the study and 267 out of 298 patients with RA gave informed consent to the imaging procedures and to the use of their data for scientific purposes. The study was performed in accordance with the Declaration of Helsinki.

\section{Imaging procedure}

All 267 individuals underwent HR-pQCT (Xtreme CT; Scanco Medical AG, Bruettisellen, Switzerland) of the second, third and fourth MCP of the most affected hand as previously described. ${ }^{25-28}$ In 242 patients with RA, image quality was high enough to allow quantitative scoring of erosions. Another four patients were excluded from further evaluation due to advanced destruction of the joints-leaving the data of 238 patients for analysis. Scans were performed at an isotropic resolution of $82 \mu \mathrm{m}$ voxel size. For the scan, the hand was placed in outstretched position in a brace and padded in order to reduce movement artefacts. Scanned region comprised 80 slices distal and maximal 253 slices proximal of the upper margin of MCP joint three; scan time was $8.6 \mathrm{~min}$.

\section{Imaging data analysis}

The number and size (width in two dimensions, depth and volume) of erosions were assessed by two independent readers $(\mathrm{CH}, \mathrm{SF})$, blinded to the identity and serological status of the patients. An erosion was defined as a pathological cortical break within bone lining. All datasets were analysed in axial, coronal and sagittal plane to detect the erosions using the open source DICOM viewer Osirix (V. 5.2). Widths and depths of erosions were assessed in two perpendicular planes. All joints were classified in four different quadrants-palmar (Q1), ulnar (Q2), dorsal (Q3) and radial (Q4). All erosions were counted, whereas the biggest erosion per quadrant was measured. Volumes were calculated using the semiellipsoid formula as described earlier $\mathrm{V}=1 / 6 \times \mathrm{w} 1 \times \mathrm{w} 2 \times \mathrm{d}^{26}$ using the widths in the two perpendicular planes as well as the deepest value of depth in one of the two respective planes (table 2 ).

\section{Statistical analysis}

First, we explored the descriptive data of the total sample and the serostatus subgroups, in order to ensure comparability of subgroups with respect to demographic background. Corresponding results are expressed as mean \pm SD for metric variables and number of individuals showing a certain characteristic for categorical variables. Comparisons between subgroups were evaluated by $\chi^{2}$ test, Kruskal-Wallis H-test, or analysis of variance (ANOVA) depending on level of measurement and fulfilment of statistical assumptions. In the context of effects of ACPAs and RF on erosive burden, we applied Games-Howell posthoc testing subsequent to ANOVA.

Subsequently, the frequency and the size of erosions were evaluated and compared inferentially by either Mann-Whitney $\mathrm{U}$ Test or (Welch-corrected) $\mathrm{t}$ test for independent samples. In this context, we tested the subgroup of RF+/ACPAs+ patients against the remaining subgroups and corrected for multiple comparisons afterwards via Bonferroni-Holm adjustment. In order to model the volume and the number of erosions while controlling for intrapatient correlation, we calculated two linear mixed models (each using an identity link function) using the following covariates: age, sex, RF/ACPA status, disease duration until image and disease activity at time of image. Additionally, we included a random intercept and a compound symmetry covariance structure. The corresponding results are expressed as robust regression coefficients, which were favoured in case of any variable in the model eventually not meeting the methodological requirements assumed with the default regression option. A $p$ value of $\mathrm{p} \leq 0.05$ was regarded statistically significant, missing values were not imputed in order to maintain the original information of the data. Inter-reader agreement was calculated using intraclass correlation coefficients (ICC). For statistical analysis, IBM SPSS V.21.0 was used.

\section{RESULTS}

\section{Patients' characteristics}

A total number of 242 patients with RA were included in this study, whereby imaging datasets from 238 patients could be analysed. Of them, 112 were double positive for RF and ACPAs $(\mathrm{RF}+\mathrm{ACPAs}+), 28$ patients positive for RF only $(\mathrm{RF}+), 29$ patients for ACPAs only (ACPAs+) and 69 patients were autoantibody negative (NEG). Patient characteristics are summarised in table 1. Overall, the subgroups were comparable with respect to age and sex distribution but differed in view of disease duration and activity, with $\mathrm{RF}+$ patients showing highest disease activity, while RF+ACPAs+ patients had longest disease duration. Mean age at time was $53.79 \pm 13.88$ years, and mean DAS28 was $3.75 \pm 1.62$ units, mean disease duration was 73.3 \pm 94.0 months and mean Health Assessment Questionaire (HAQ) was $0.97 \pm 0.78$ units resembling a population of established patients with RA, with low-to-high disease activity. More than half the patients received conventional antirheumatic treatment with methotrexate as the leading DMARD, whereas roughly one-third of the patients received biological DMARD treatment (for details see table 1). The majority of the patients $(67 \%)$ were starting antirheumatic treatment at time of the measurement, or were within the first year of their treatment.

\section{Prevalence of bone erosion dependent on ACPAs and RF status}

HR-pQCT scans from 714 individual joints of 5712 sites were evaluated for the presence and size of bone erosions. These analyses revealed a total number of 897 erosions, which were examined for their size by assessing erosion width, depth and volume. Examples for bone erosions in the different groups are shown in figure 1. Prevalence of bone erosions was highest in the $\mathrm{RF}+\mathrm{ACPAs}+$ patients $(\mathrm{N}=599 ; \mathrm{N} /$ patient $=5.35 ; \mathrm{N} /$ patient $/$ joint $=1.78)$ compared with the other subgroups of patients with RA (N/patient: RF +2.00; ACPAs +2.41; NEG 2.49). In this context, inferential significance was found for the comparison of RF+ACPAs + with NEG $\mathrm{t}(147.28)=3.45, \mathrm{p}=0.001$ while trends were observed for the other subgroups when compared with RF+ACPAs+ (RF+: $U=1205.50, \quad z=-1.91$, $\mathrm{p}=0.056$; ACPAs $+: \mathrm{U}=1297.00, \mathrm{z}=-1.69, \mathrm{p}=0.091)$. Further details are shown in table 2. Distribution of erosions was similar among the four subgroups with dominant involvement of the MCP2 joint as previously reported. ${ }^{23}$ About $25 \%$ of the patients did not reveal signs of bone erosions. The ICC for inter-reader reliability for erosion numbers was high (0.872-1.000). 
Table 1 Patients' characteristics

\begin{tabular}{|c|c|c|c|c|c|c|}
\hline Group & Total sample & $\mathrm{RF}+$ /ACPAs+ & $\mathrm{RF}+$ & ACPAs+ & Negative & Inferential test coefficients, $\mathrm{p}$-value \\
\hline $\mathrm{N}$ (total) & 238 & 112 & 28 & 29 & 69 & - \\
\hline Females N (\%) & $181(76.7)$ & $81(72.3)$ & $23(81.1)$ & $24(82.7)$ & $53(76.8)$ & $\chi^{2}(3)=2.16, p=0.54$ \\
\hline Age (years) & $53.79 \pm 13.88$ & $53.97 \pm 13.39$ & $50.36 \pm 15.37$ & $53.14 \pm 13.81$ & $55.16 \pm 14.12$ & $F(3,234)=0.82, p=0.48$ \\
\hline Disease duration (months) & $73.31 \pm 94.05$ & $94.78 \pm 104.81$ & $52.57 \pm 72.91$ & $70.07 \pm 91.82$ & $48.18 \pm 75.71$ & $H(3)=11.76, p=0.008$ \\
\hline DAS28 (Units) & $3.75 \pm 1.62$ & $3.65 \pm 1.55$ & $4.42 \pm 1.56$ & $2.98 \pm 1.10$ & $3.96 \pm 1.80$ & $F(3,232)=4.52, p=0.004$ \\
\hline ACPA (Units) & $156.91 \pm 267.33$ & $286.84 \pm 331.53$ & $2.01 \pm 1.79$ & $169.34 \pm 127.39$ & $1.50 \pm 1.21$ & $H(3)=233.03, p<0.001$ \\
\hline RF (Units) & - & $248.44 \pm 441.83$ & $117.16 \pm 243.84$ & $<20$ & $<20$ & ${ }^{*} U=979, z=-3.07, p=0.002$ \\
\hline Methotrexate (\%) & $97(40.7)$ & $48(42.9)$ & $11(39.3)$ & $13(44.8)$ & $25(36.2)$ & - \\
\hline Other (\%) DMARDs (\%) & $40(16.8)$ & $18(16.1)$ & $4(14.3)$ & $7(24.0)$ & $11(16.0)$ & - \\
\hline TNF-Inhibitors & $49(20.5)$ & $31(27.7)$ & $4(14.3)$ & $6(20.7)$ & $8(11.6)$ & - \\
\hline Other biologicals & $21(8.8)$ & $12(10.7)$ & $4(14.3)$ & $2(6.9)$ & $3(4.3)$ & - \\
\hline
\end{tabular}

Values are means \pm SD

${ }^{*}$ Mann-Whitney U-test.

ACPA, anticitrullinated protein antibodies; DAS 28, disease activity score 28; DMARDS, disease-modifying antirheumatic drugs; RF, rheumatoid factor; TNF, tumour necrosis factor.

\section{Size of bone erosion dependent on ACPAs and RF status}

When assessing the size of erosions, we found the highest average erosion volume in ACPAs + patients (RF+/ACPAs+: $7.66 \pm 12.18 \mathrm{~mm}^{3}$, ACPAs+: $6.20 \pm 9.50 \mathrm{~mm}^{3}, \mathrm{RF}+: 2.76$ $\pm 3.17 \mathrm{~mm}^{3}$, NEG: $3.32 \pm 6.25 \mathrm{~mm}^{3}$ ). Interestingly, ACPApositive subgroups did not differ from each other $(t(460)$ $=0.844, \mathrm{p}=0.399$ ) while differences between ACPA-positive and ACPA-negative subgroups were observed (RF+/ACPAs+ vs $R F+: \mathrm{t}(256.57)=6.435, \mathrm{p}<0.001 ; \mathrm{RF}+\mathrm{ACPAs}+\mathrm{vs} \mathrm{NEG}: \mathrm{t}$ $(473.44)=5.418, \mathrm{p}<0.001 ;$ ACPAs + vs RF+: $\mathrm{t}(66.23)=2.504$, $\mathrm{p}=0.015$; ACPAs + vs NEG: $\mathrm{t}(71.17)=2.06, \mathrm{p}=0.043)$, suggesting larger erosions in ACPA-positive patients. Even after Bonferroni-Holm adjustment for multiple comparisons, only one out of five comparisons (ACPAs + vs NEG, $\mathrm{p}=0.043$ ) did not maintain significance (critical $\mathrm{p}$ value for this comparison: $\mathrm{p}=0.025$ ). Further details on erosion width, depth, and volume can be taken from table 2 .

\section{Occurrence and volume of erosions in a multivariate setting}

In order to control for potential confounders and to account for intrapatient correlation, we performed two linear mixed models: one for numbers, the other for volumes of erosions.
Independent variables were the four subgroups according to serostatus, as well as age, gender, disease duration and disease activity at time of imaging (table 3 ). Both multivariate models confirmed an independent synergistic effect of RF and ACPAs positivity, as only RF+ACPAs + patients were significantly different from the double negative reference group in view of both outcomes (number of erosions: $\mathrm{t}=2.441 ; \mathrm{p}=0.017$, volume of erosions: $\mathrm{t}=2.582 ; \mathrm{p}=0.014)$. Additionally, longer disease duration also contributes to higher prevalence and size of erosions (number of erosions: $t=3.713$ and $p=0.005$, volume of erosions: $\mathrm{t}=3.335 ; \mathrm{p}=0.013)$. By contrast, disease activity relates to the prevalence of erosions only $(\mathrm{t}=3.870 ; \mathrm{p}<0.001)$, whereas gender and age did not relate to erosion prevalence or size.

\section{Additive effect of ACPAs and RF on erosive burden of RA}

We next addressed the effect of ACPAs and RF titres and their mutual relation on bone erosions in RA. Therefore, we compared the sum of erosion volume in patients with a negative RF $(<20 \mathrm{U})$ and those with low $(20-100 \mathrm{U})$ and high $(>100 \mathrm{U})$ values. According to a corresponding ANOVA, these subgroups differed significantly $\mathrm{F}(2,235)=7.32, \mathrm{p}<0.001$, whereas in

Table 2 Characteristics of bone erosions

\begin{tabular}{|c|c|c|c|c|}
\hline Group & $\mathrm{RF}+/$ ACPAs+ & RF+ & ACPAs+ & Negative \\
\hline Erosions (N) & 599 & 56 & 70 & 172 \\
\hline Erosion/patient (N) & 5.35 & 2 & 2.41 & 2.49 \\
\hline Erosion/patient/joint (N) & 1.78 & 0.67 & 0.80 & 0.83 \\
\hline Erosion width $1 /$ quadrant $(\mathrm{mm})$ & $0.31 \pm 0.88$ & $0.11 \pm 0.44$ & $0.15 \pm 0.60$ & $0.12 \pm 0.44$ \\
\hline Erosion width $2 /$ quadrant $(\mathrm{mm})$ & $0.29 \pm 0.87$ & $0.10 \pm 0.40$ & $0.14 \pm 0.56$ & $0.13 \pm 0.47$ \\
\hline Erosion depth/quadrant $(\mathrm{mm})$ & $0.35 \pm 1.08$ & $0.13 \pm 0.54$ & $0.18 \pm 0.76$ & $0.17 \pm 0.71$ \\
\hline Erosion volume/quadrant $\left(\mathrm{mm}^{3}\right)$ & $1.17 \pm 5.48$ & $0.20 \pm 1.11$ & $0.48 \pm 3.11$ & $0.28 \pm 2.23$ \\
\hline Erosion width 1/patient (mm) & $2.05 \pm 1.23$ & $1.54 \pm 0.69$ & $1.96 \pm 1.09$ & $1.45 \pm 0.62$ \\
\hline Erosion width 2 patients $(\mathrm{mm})$ & $1.92 \pm 2.22$ & $1.42 \pm 0.63$ & $1.83 \pm 1.06$ & $1.51 \pm 0.72$ \\
\hline Erosion depth/patient (mm) & $2.28 \pm 2.75$ & $1.85 \pm 0.98$ & $2.37 \pm 1.57$ & $2.03 \pm 1.45$ \\
\hline Erosion/volume/patient $\left(\mathrm{mm}^{3}\right)$ & $7.66 \pm 12.18$ & $2.76 \pm 3.17$ & $6.20 \pm 9.50$ & $3.32 \pm 6.25$ \\
\hline
\end{tabular}

ACPA, anticitrullinated protein antibodies, RF, rheumatoid factor; width 1, axial plain ; width 2, sagittal plain; values are means \pm SD.

Inferential comparisons with respect to erosion volume:

$R F+A C P A s+$ versus $R F+t(256.57)=6.435, p<0.001$ (critical $p=0.01$ ).

$\mathrm{RF}+\mathrm{ACPAs}+$ versus NEG $\mathrm{t}(473.44)=5.418, \mathrm{p}<0.001$ (critical $\mathrm{p}=0.013$ ).

ACPAs+ versus $R F+t(66.23)=2.504, p=0.015$ (critical $p=0.017$ ).

ACPAs+ versus NEG $t(71.17)=2.06, p=0.043$, (critical $p=0.025$ ).

$\mathrm{RF}+\mathrm{ACPAs}+$ versus ACPAs+ t(460) $=0.844, \mathrm{p}=0.399$, (critical $\mathrm{p}=0.05$ ). 


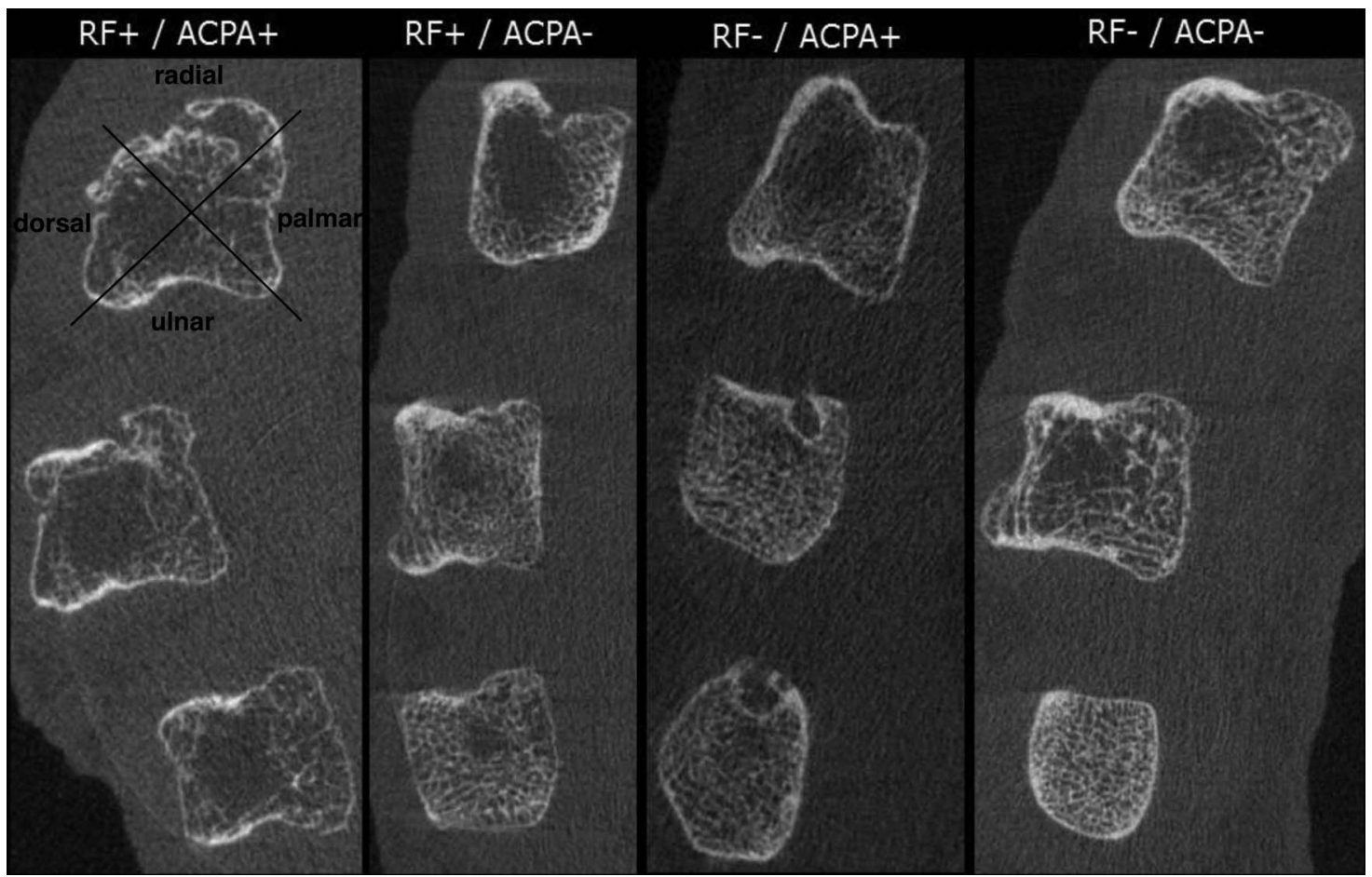

Figure 1 Representative CT scans of bone erosions. The images show CT scans metacarpal heads 2, 3 and 4 of patients with rheumatoid arthritis either double-positive for anti-citrullinated protein antibodies and rheumatoid factor (ACPA+/RF+), single positive for $R F(R F+/ A C P A-)$, single positive for ACPA (RF-IACPA+) and negative for both autoantibodies (RF-IACPA-).

corresponding posthoc comparisons, only patients with high RF values differed in erosion volume compared with RF negative patients $\left(\Delta\right.$ means $\left.=27.61, \quad \mathrm{SE}=10.24, \quad \mathrm{p}_{\text {Games-Howell }}=0.025\right)$. When comparing cumulative erosion volume in patients with RA without ACPAs (<10 U), low/moderate ACPAs (10-100 U) and high $(>100 \mathrm{U})$ ACPAs, we again found differences in erosion volumes $\mathrm{F}(2,235)=5.13, \mathrm{p}<0.007$. Posthoc comparisons revealed that ACPA patients differed from patients having low $/$ moderate $\quad\left(\Delta\right.$ means $=-18.98, \quad \mathrm{SE}=7.71, \quad \mathrm{p}_{\mathrm{Games}}$ Howell $=0.046)$ and high ACPA levels ( $\Delta$ means $=-18.13$, $\left.\mathrm{SE}=6.02, \quad \mathrm{p}_{\text {Games-Howell }}=0.009\right)$, suggesting larger erosions volumes in the latter. Furthermore, when comparing the impact of RF on cumulative erosion volume in ACPA-negative and ACPA-positive patients with RA, it became evident that RF enhances the burden of erosions in ACPA-positive but not ACPA-negative patients (figures 2A, B). Similar results were also found for the erosion numbers (figure $2 \mathrm{~B}$ ) and also in the subset of patients with RA with $<3$ years of disease duration (see online supplementary figure S1).

\section{DISCUSSION}

Here, we show that the concomitant presence of RF and ACPAs is associated with more severe erosive bone damage in patients with RA. Compared with patients with RA negative for either $\mathrm{RF}$ and/or ACPAs, our results suggest an increased number of bone erosions and an increased size of the individual lesions in $\mathrm{RF}+\mathrm{ACPAs}+$ patients. Although the erosive disease burden was higher in mere ACPA-positive patients than in seronegative or

Table 3 Linear mixed model for numbers as well as volumes of erosions

\begin{tabular}{|c|c|c|c|c|c|c|c|c|c|}
\hline \multicolumn{5}{|l|}{ Erosion number } & \multicolumn{5}{|l|}{ Erosion volume } \\
\hline & $\begin{array}{l}\text { Regression } \\
\text { coefficients }\end{array}$ & $95 \% \mathrm{Cl}$ & p Values & $\mathrm{t}$-Values & & $\begin{array}{l}\text { Regression } \\
\text { coefficients }\end{array}$ & $95 \% \mathrm{Cl}$ & $p$ Values & $\mathrm{t}$-Values \\
\hline Intercept & -0.112 & -0.230 to 0.006 & 0.062 & -1.900 & Intercept & -0.820 & -1.758 to 0.117 & 0.083 & -1.827 \\
\hline Age (years) & 0.001 & -0.001 to 0.003 & 0.205 & 1.277 & Age (years) & 0.007 & -0.004 to 0.018 & 0.196 & 1.323 \\
\hline Male Gender & -0.017 & -0.076 to 0.042 & 0.568 & -0.573 & Male Gender & -0.089 & -0.500 to 0.321 & 0.663 & -0.439 \\
\hline RF+/ACPAs+ & 0.072 & 0.013 to 0.132 & 0.017 & 2.441 & RF+/ACPAs+ & 0.518 & 0.111 to 0.924 & 0.014 & 2.582 \\
\hline $\mathrm{RF}+$ & -0.042 & -0.104 to 0.021 & 0.179 & -1.391 & $\mathrm{RF}+$ & -0.163 & -0.586 to 0.259 & 0.346 & -1.065 \\
\hline ACPAs+ & -0.014 & -0.072 to 0.044 & 0.601 & -0.543 & ACPAs+ & 0.028 & -0.383 to 0.438 & 0.874 & 0.166 \\
\hline DAS28 (units) & 0.028 & 0.014 to 0.043 & $<0.001$ & 3.870 & DAS28 (Units) & 0.097 & -0.020 to 0.214 & 0.100 & 1.716 \\
\hline $\begin{array}{l}\text { Disease duration } \\
\text { (months) }\end{array}$ & 0.001 & 0.000 to 0.002 & 0.005 & 3.713 & $\begin{array}{l}\text { Disease duration } \\
\text { (months) }\end{array}$ & 0.008 & 0.002 to 0.014 & 0.013 & 3.335 \\
\hline
\end{tabular}

Bold numbers indicate significant associations.

In both models, negative (NEG) patients were declared the reference subgroup. Therefore, significant results for RF+ACPAs+ subgroup indicate differences in comparison with NEG patients.

ACPA, anticitrullinated protein antibodies; DAS 28 , disease activity score 28 ; RF, rheumatoid factor. 
A

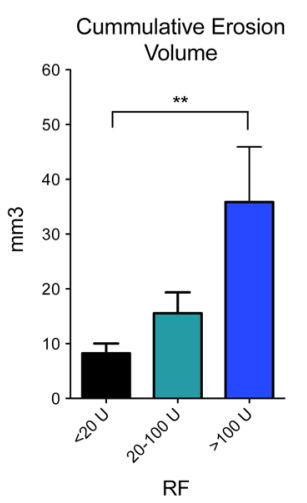

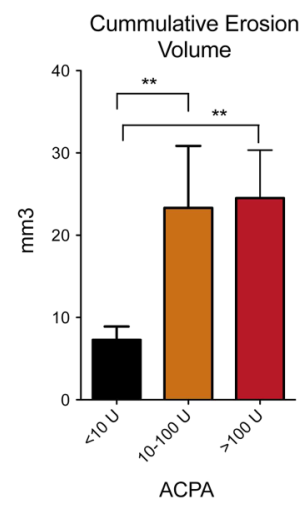
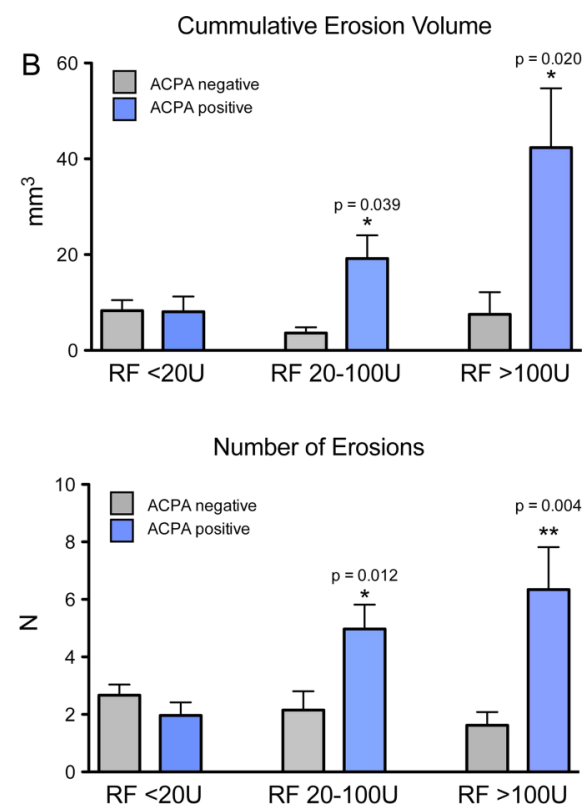

Figure 2 Additive effect of anticitrullinated protein antibodies (ACPAs) and rheumatoid factor (RF) on bone erosion in patients with rheumatoid arthritis. (A) Mean cumulative erosion volumes ( $\mathrm{mm}^{3}$ ) in subgroups based on RF (left) and ACPAs (right); (B) mean cumulative erosion volumes and erosion numbers in subgroups based on RF and ACPAs. Asterisks indicate significant differences.

mere RF-positive patients, it was still lower than in those patients with double positivity for RF and ACPAs. These observations suggest that RF may act as an enhancer of bone loss in patients with RA, and acts as an additive to ACPAs.

$\mathrm{RF}$ and ACPAs are the key autoimmune responses in patients with RA. Both autoantibody entities have been associated with a more severe disease course in patients with RA. Stunningly, however, most studies have either focussed on the role of RF or ACPAs as an individual entity, whereas only few studies have addressed the interdependence for RA disease presentation. ${ }^{7} 2930$ This situation is most likely based on the fact that RF was en vogue till the $1990 \mathrm{~s}$, but interest on RF has faded later and has been gradually replaced by growing research in citrullinated proteins as autoantigens in RA. Nonetheless, RF and ACPAs cannot be seen isolated since there is a substantial overlap in the prevalence of both autoantibody species in patients with RA.

Several studies have shown that ACPAs are related to enhanced bone loss in patients with RA showing faster development of bone erosions and more pronounced changes of the cortical and trabecular bone mass and architecture. ${ }^{7-12} 2021$ Furthermore, ACPA titre has been linked to the potential of RA to cause bone loss. ${ }^{29} 31$ This finding may be explained by the fact that ACPAs can directly induce osteoclast differentiation in vitro and in vivo, suggesting that ACPAs are causally involved in bone loss of RA. ${ }^{19}$ Our data support this concept but also show that the effect of ACPAs on bone is even more pronounced when RF is present.

Analysis on the effect of RF on the bone in patients with RA goes back to the $1970 \mathrm{~s}$ and $1980 \mathrm{~s}$, showing that bone erosions are larger and more frequent in RA patients with RF than in those without RF. ${ }^{13-15}$ At these times ACPAs had not been discovered yet. Later studies confirmed these data suggesting that the presence of RF indeed represents a risk factor for developing bone erosions, which is independent from other diseasespecific factors. ${ }^{16-18}$ How the findings of these studies relate to the concomitant presence of ACPAs in patients with RA displaying a RF response, however, remained unclear. Our data suggest that it indeed matters where there is concomitant presence of
ACPAs in such patients. Hence, our data show that RF becomes important for bone erosions when ACPAs are present. In patients who are ACPA-negative, the number and size of erosions are low, independent of whether RF is positive or negative. By contrast, the burden of erosion massively increased, dependent on the RF responses, when patients with positive ACPAs are analysed.

Although previous studies have shown that ACPAs can induce osteoclast differentiation without RF, these data clearly suggest that there is an effect of RF on bone loss. RF is an immune complex per definition, and cross-linking of such immune complexes could represent a strong enhancer for activation of cells of the monocyte/macrophage lineage. Immune complexes can induce cytokine expression in monocytes and trigger an inflammatory response. ${ }^{24}$ Some of these cytokines, in particular, tumour necrosis factor (TNF)- $\alpha$, are known as potent inducers of osteoclast differentiation and bone resorption. Osteoclast lineage cells also express $F_{c}$ receptors, which make them responsive to immune complexes and, therefore, also RF, further supporting the role of RF in RA-mediated bone loss. ${ }^{32}$

A limitation of this study is its cross-sectional character not allowing a conclusion on potential additive effects of ACPAs and RF on the progression of bone erosion. Although our data strongly support such concepts, final conclusion will depend on a longitudinal study. Other limitations are based on the comparatively small group size of single-autoantibody-positive patients, which is due to the paucity of such patients. However, we think that we could overcome this challenge by analysing a rather large cohort of patients with RA in the HR-pQCT. The focus on imaging of the hand joints can be seen as another limitation of this study, since they may not completely reflect the global burden of bone erosions in the body. However, since hand joints are the key anatomical site affected in RA, the assessment of bone damage at this anatomical site is likely being representative for global bone damage.

In summary, our data show the interdependence of ACPAs and RF in RA-mediated bone loss. The combination of both antibodies additively increases the burden of bone erosion in 
RA, which is most likely based on the ACPA-specific mechanism, as previously described, and immune complex mediated mechanisms related to RF. In fact, RF appears to be a strong enhancer of ACPA-mediated bone loss, a concept, which further substantiated the pathogenic role of autoantibody responses in patients with RA. Hence, the data re-emphasise the importance of autoimmunity for structural damage in patients with RA. Next to synovial inflammation and related cytokine expression, autoimmunity has to be considered as an important precipitator for bone loss in RA. Additionally, our data revisit the role of RF in RA, suggesting that RF serves as an enhancer for structural damage in patients with RA.

Contributors $\mathrm{CH}, \mathrm{SS}, \mathrm{EA}$ and KE collected and analysed the data. SF, JR and GS designed the study. ME, CH and SF performed statistical analyses. CH, SF and GS wrote the manuscript.

Funding This study was supported by the Deutsche Forschungsgemeinschaft (SPP1468-IMMUNOBONE), the Bundesministerium für Bildung und Forschung (BMBF; project ANCYLOSS), the Marie Curie project OSTEOIMMUNE, the TEAM and MASTERSWITCH projects of the European Union and the IMI-funded project BTCure. The present work was the MD thesis of Carolin Hecht.

Competing interests None.

Patient consent Obtained.

Ethics approval University of Erlangen-Nuremberg.

Provenance and peer review Not commissioned; externally peer reviewed.

\section{REFERENCES}

1 McInnes IB, Schett $\mathrm{G}$. The pathogenesis of rheumatoid arthritis. N Engl J Med 2011;365:2205-19.

2 Geusens P, Lems WF. Osteoimmunology and osteoporosis. Arthritis Res Ther 2011;13:242.

3 Haugeberg G, Orstavik RE, Kvien TK. Effects of rheumatoid arthritis on bone. Curr Opin Rheumtol 2003;15:469-75.

4 De Rycke L, Peene I, Hoffman IE, et al. Rheumatoid factor and anticitrullinated protein antibodies in rheumatoid arthritis: diagnostic value, associations with radiological progression rate, and extra-articular manifestations. Ann Rheum Dis 2004;63:1587-93.

5 Klareskog L, Stolt P, Lundberg K, et al. A new model for an etiology of rheumatoid arthritis: smoking may trigger HLA-DR (shared epitope)-restricted immune reactions to autoantigens modified by citrullination. Arthritis Rheum. 2006;54:38-46.

6 Aletaha D, Neogi T, Silman AJ, et al. 2010 Rheumatoid arthritis classification criteria: an American College of Rheumatology/ European League Against Rheumatism collaborative initiative. Ann Rheum Dis 2010;69:1580-8.

7 Kroot EJ, de Jong BA, van Leeuwen MA, et al. The prognostic value of anti-cyclic citrullinated peptide antibody in patients with recent-onset rheumatoid arthritis. Arthritis Rheum 2000;43:1831-5.

8 van der Helm-van Mil AH, Verpoort KN, Breedveld FC, et al. Antibodies to citrullinated proteins and differences in clinical progression of rheumatoid arthritis. Arthritis Res Ther 2005;7:R949-958.

9 Syversen SW, Goll GL, van der Heijde D, et al. Prediction of radiographic progression in rheumatoid arthritis and the role of antibodies against mutated citrullinated vimentin: results from a 10-year prospective study. Ann Rheum Dis 2010;69:345-51.

10 Hetland ML, Stengaard-Pedersen K, Junker P, et al. Radiographic progression and remission rates in early rheumatoid arthritis-MRI bone oedema and anti-CCP predicted radiographic progression in the 5-year extension of the double-blind randomised CIMESTRA trial. Ann Rheum Dis 2010;69:1789-95.

11 Kocijan R, Finzel S, Englbrecht $M$, et al. Differences in Bone Structure between Rheumatoid Arthritis and Psoriatic Arthritis Patients depend on autoantibody positivity. Ann Rheum Dis 2014;73:2022-8.
12 Kleyer A, Finzel S, Rech J, et al. Bone loss before the clinical onset of rheumatoid arthritis in subjects with anticitrullinated protein antibodies. Ann Rheum Dis 2014;73:854-60.

13 Masi AT, Maldonado-Cocco JA, Kaplan SB, et al. Prospective study of the early course of rheumatoid arthritis in young adults: comparison of patients with and without rheumatoid factor positivity at entry and identification of variables correlating with outcome. Semin Arthritis Rheum 1976;4:299-326.

14 Burns TM, Calin A. The hand radiograph as a diagnostic discriminant between seropositive and seronegative 'rheumatoid arthritis': a controlled study. Ann Rheum Dis 1983:42:605-12.

15 el-Khoury GY, Larson RK, Kathol MH, et al. Seronegative and seropositive rheumatoid arthritis: radiographic differences. Radiology 1988;168:517-20.

16 Goronzy JJ, Matteson EL, Fulbright JW, et al. Prognostic markers of radiographic progression in early rheumatoid arthritis. Arthritis Rheum 2004;50: 43-54.

17 Bukhari M, Lunt M, Harrison BJ, et al. Rheumatoid factor is the major predictor of increasing severity of radiographic erosions in rheumatoid arthritis: results from the Norfolk Arthritis Register Study, a large inception cohort. Arthritis Rheum 2002;46:906-12.

18 Aletaha D, Alasti F, Smolen JS. Rheumatoid factor determines structural progression of rheumatoid arthritis dependent and independent of disease activity. Ann Rheum Dis 2013;72:875-80.

19 Harre U, Georgess D, Bang H, et al. Induction of osteoclastogenesis and bone loss by human autoantibodies against citrullinated vimentin. J Clin Invest 2012;122:1791-802.

20 Guler-Yuksel M, Allaart CF, Goekoop-Ruiterman YPM, et al. Changes in hand and generalised bone mineral density in patients with recent-onset rheumatoid arthritis. Ann Rheum Dis 2009;68:330-6.

21 Vencovsky J, Machacek S, Sedova L, et al. Autoantibodies can be prognostic markers of an erosive disease in early rheumatoid arthritis. Ann Rheum Dis 2003;62:427-30.

22 Rantapää-Dahlqvist $\mathrm{S}$, de Jong BA, Berglin E, et al. Antibodies against cyclic citrullinated peptide and IgA rheumatoid factor predict the development of rheumatoid arthritis. Arthritis Rheum 2003:48:2741-9.

23 Van Schaardenburg D, Nielen MM, Lems WF, et al. Bone metabolism is altered in preclinical rheumatoid arthritis. Ann Rheum Dis 2011;70:1173-4.

24 Laurent L, Clavel C, Lemaire 0 , et al. Fc\{gamma\} receptor profile of monocytes and macrophages from rheumatoid arthritis patients and their response to immune complexes formed with autoantibodies to citrullinated proteins. Ann Rheum Dis 2011;70:1052-9.

25 Stach CM, Bauerle M, Englbrecht $M$, et al. Periarticular bone structure in rheumatoid arthritis patients and healthy individuals assessed by high-resolution computed tomography. Arthritis Rheum 2010;62:330-9.

26 Finzel S, Rech J, Schmidt S, et al. Repair of bone erosions in rheumatoid arthritis treated with tumour necrosis factor inhibitors is based on bone apposition at the base of the erosion. Ann Rheum Dis 2011;70:1587-93.

27 Finzel S, Rech J, Schmidt S, et al. Interleukin-6 receptor blockade induces limited repair of bone erosions in rheumatoid arthritis: a micro CT study. Ann Rheum Dis 2013;72:396-400.

28 Albrecht $\mathrm{A}$, Finzel $\mathrm{S}$, Englbrecht $\mathrm{M}$, et al. The structural basis of MRI bone erosions: an assessment by microCT. Ann Rheum Dis 2013;72:1351-7.

29 Berglin E, Johansson T, Sundin U, et al. Radiological outcome in rheumatoid arthritis is predicted by presence of antibodies against cyclic citrullinated peptide before and at disease onset, and by IgA-RF at disease onset. Ann Rheum Dis 2006;65:453-8.

30 Forslind K, Ahlmén M, Eberhardt K, et al. ARFOT Study Group. Prediction of radiological outcome in early rheumatoid arthritis in clinical practice: role of antibodies to citrullinated peptides (anti-CCP). Ann Rheum Dis 2004;63: 1090-5.

31 Syversen SW, Gaarder PI, Goll GL, et al. High anti-cyclic citrullinated peptide levels and an algorithm of four variables predict radiographic progression in patients with rheumatoid arthritis: results from a 10-year longitudinal study. Ann Rheum Dis 2008;67:212-17.

32 Seeling M, Hillenhoff U, David JP, et al. Inflammatory monocytes and Fcgamma receptor IV on osteoclasts are critical for bone destruction during inflammatory arthritis in mice. Proc Natl Acad Sci USA 2013;110:10729-34. 


\section{ARD Additive effect of anti-citrullinated protein antibodies and rheumatoid factor on bone erosions in patients with RA}

Carolin Hecht, Matthias Englbrecht, Jürgen Rech, Sarah Schmidt, Elizabeth Araujo, Klaus Engelke, Stephanie Finzel and Georg Schett

Ann Rheum Dis 2015 74: 2151-2156 originally published online August 12,2014

doi: 10.1136/annrheumdis-2014-205428

Updated information and services can be found at:

http://ard.bmj.com/content/74/12/2151

These include:

Supplementary Supplementary material can be found at:

Material http://ard.bmj.com/content/suppl/2014/08/13/annrheumdis-2014-2054 28.DC1

References This article cites 32 articles, 19 of which you can access for free at: http://ard.bmj.com/content/74/12/2151\#BIBL

Email alerting Receive free email alerts when new articles cite this article. Sign up in the service box at the top right corner of the online article.

Collections

Articles on similar topics can be found in the following collections

Connective tissue disease (4253)

Degenerative joint disease (4641)

Immunology (including allergy) (5144)

Musculoskeletal syndromes (4951)

Rheumatoid arthritis (3258)

\section{Notes}

To request permissions go to:

http://group.bmj.com/group/rights-licensing/permissions

To order reprints go to:

http://journals.bmj.com/cgi/reprintform

To subscribe to BMJ go to:

http://group.bmj.com/subscribe/ 